\title{
Bioformulation and Nanotechnology in Pesticide and Fertilizer Delivery System for Eco-Friendly Agriculture: A Review
}

\author{
Pragati Sahai ${ }^{1}$, Vimlendu Bhushan Sinha ${ }^{1}$ and Rajiv Dutta ${ }^{2 *}$ \\ ${ }^{1}$ Department of Biotechnology, School of Engineering and Technology, Sharda University, India \\ ${ }^{2}$ QNS Chair Honorary Professor, Department of Life Sciences, Faculty of Applied Sciences, Dr. KN Modi University, Rajasthan, India \\ *Corresponding Author: Rajiv Dutta, QNS Chair Honorary Professor, Department of Life Sciences, Faculty of Applied Sciences, Dr. KN \\ Modi University, Rajasthan, India.
}

Received: April 01, 2019; Published: October 05, 2019

DOI: 10.31080/ASAG.2019.03.0675

\begin{abstract}
The agriculturist and environmentalist designed certain green practices like bioformulation, to eradicate the problems of biomagnifications and chemical toxicity in the environment. However the green practices that have been designed and implicated, almost all of them had delivery constraints and to minimise this effective delivery model was needed. The researchers then identified different delivery models from solid to liquid to dust that were harmless, stable, and inert. These delivery models were called as Carriers. The role of carriers was very fast. This delivery system was designed as per the agricultural need for that specific crop growth requirement. Hence the same carrier if acted as biofertilizers in one crop, acted as biocontrol agent/ biopesticide in another crop. Similarly, the carriers in the formulation were also used in post-harvest technology to increase the shelf life of the crops and also to act as effective biocontrol agent as inducing resistance in crops against pest. Various types of carriers have been studied and applied but the rate of biocontrol is still yet to reach the optimum, therefore the use of nanofertilizers or nanoparticles as carriers also was studied and it was found to be very effective, however the toxicity due to its accumulation in nature is yet to evaluated and so it also has its own constraints. This review throws light on different carrier systems, the effective bioformulations and use of nanotechnology in agriculture. The review is basically the study of some experimental procedures on certain standard crops divided in different segments so that the methodology and the results can be used for future scope and interventions.
\end{abstract}

Keywords: Biofertilizers; Bioformulation; Nanotechnology; Pesticide

\section{Introduction}

The plant diseases affecting the cultivation and production of crops are serious concerns in agriculture as it largely affects the quality and quantity of the produce. The population increase leads to a greater demand for food. Since food is the basic necessity for life, the human population cannot compromise on food security, not even at the cost of earth's sustainability. It has been estimated in 2015 that the current global population, is two to three times higher than can be sustained by current food production levels and is already utilizing $50 \%$ more resources than the earth is producing [1]. Consequently, our overburdened resources are declining very rapidly. There are 50000 species of bacterial and fungal phytopathogens; and 8000 species of weeds which largely reduce crop yield and quality and therefore chemical pesticides have become an utmost necessity for crop cultivation not only at all stages of their growth but also during postharvest storage. But the use of pesticides has exerted a selection pressure on pests and pathogens which forced them to adapt according to their chemically modified habitats, and a consequence has been the evolution of 'pesticideresistant' varieties [2]. Secondly, the practice led to deposition of pesticide residue in food crops that eventually entered the food chain leading to biomagnifications of the pesticide [3]. Therefore biocontrol has been found to be the best practice in controlling the plant pathogens and bacterial biopesticides are target-specific, rapidly multiplying, easy to handle, nontoxic, and economically suitable organisms with better survival and longevity [4] (Figure 1). The field use of bio inoculation or bio formulation is largely hampered by the lack of suitable carrier. As a part of green revolution and taking a holistic approach bioformulation can be defined as a ready-to-use formulation, containing living cells or their metabolites (of one or more strains), supported by nontoxic and inert compounds called CARRIERS to maintain the viability and efficiency of cells or metabolites and to increase their shelf life. But the various bioformulation types like liquid formulation; dust formulation etc. also exhibited constraints in delivery [5]. Therefore the scientists have been in process of finding effective Carrier to introduce bio formulation in to the soil. The vehicle that is used to deliver the live microorganism from in-vitro conditions (laboratory) to in-vivo conditions (Field) is known as Carrier. 


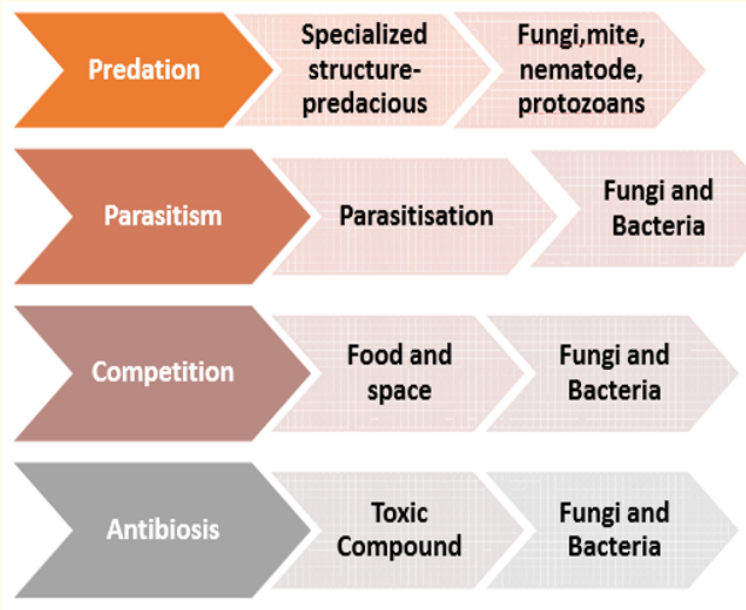

Figure 1: Different mechanism of Biocontrol.

Incorporation of microorganisms in carrier material enables easy-handling, long-term storage and high effectiveness of biofertilizers [6]. Secondly the incorporation of microorganism to carrier is by simple procedure. According to the "Handbook for Rhizobia" [7], the properties of a good carrier material for seed inoculation are: (1) non-toxic to inocula and bacterial strain (2) good moisture absorption capacity (3) easy to process and free of lump-forming materials (4) easy to sterilize by autoclaving or gamma-irradiation (5) available in adequate amounts (6) inexpensive (7) good adhesion to seed or sand (8) good pH buffering capacity and (9) nontoxic to plants.

There are four types of carrie rs viz: Soil (Peat), Plant waste materials (saw dust), inert materials (Vermiculite) and plain lyophilized microbial culture (bioformulation of Rhizobiium and Azospirillum). The carrier along with inoculants comes in four dispersal form as in powders, slurries, liquids and granules. However in 1984 a research group told about lignite-stillage carrier system for biocontrol of fungal pathogen [1]. This carrier system was not only easy and economical but it acted as nutrient culture for biocontrol agent and was unique in the study as carrier and substrate system for impregnation of biocontrol agent to soil. After this study many carrier-substrate system were made for application of biocontrol agent [9]. The quality of bioinoculants largely decide their fate in agriculture [10]. It was found that in solid/liquid formulation when different combinations of microorganism in different carriers were made then the output was different even for the same microorganism. For an example, if Rhizobium is the micro organism to be inoculated effectively, it is impregnated in different carriers to form different formulation and when each formulation was put to test, the nodulation efficiency was found to be different in each case. The Plant Growth Promoting Rhizobium (PGPR) are class of bacteria that inhabit the rhizosphere and helps in increasing the fertility of the soil and promote growth by at least one mechanism i.e. in the form of Biofertilizers or Biostimulants or Bioprotectants [11]. The use of carriers are now the most widely used application in plant agro system and various research groups are coming up with different carriers in order to meet the agricultural demand. The carrier based inoculation is also gaining importance as biopesticide for remediation of agricultural land from insects and other pests. The increasing pollution and heavy metal deposition by extensive use of chemical fertilizers and pesticides has led to leaching of pollutants in water bodies or increased soil toxicity due to direct absorption through environment. Even acid rains add to salinity in soil that needs to be treated at priority as it makes soil gradually impotent and non-fertile bringing greater loss to farmers.

The effective use of carrier based formulations as biofertilizers has been explored as beneficial to soil in increasing its nutrient uptake. When this formulation was used as biofertilizers, they also exhibited property of metal bioleaching and metal degradation that generated the possible use of this formulation for treatment of agricultural land. Similarly if the carriers were used as biopesticide they not only exhibited pesticidal properties but also enhanced the growth of plant. Thus a carrier that can be acting as biofertilizers can also exhibit pesticidal properties. The recent advancements in agriculture sector has widely shown the use of nanoparticles in one form or the other for benefit of the sector [12], therefore the use of such magic particles with various application in field of agriculture led to their efficacy and toxicity assay as well so that the accumulation of nanoparticles does not harm the environment.

In this review the methodology so adopted will be discussed from where the inference of the role of carrier primarily as biofertilizers and secondary as biopesticide will be explored so that the better understanding of its application and its role in plant agro system can be studied. Lastly to explore the knowledge in new advancements in agriculture, the role of Nanotechnology will also be explored.

The methodology discussed in the review caters to the methods adopted to meet the above objectives and was effective in explaining the different types of carriers prepared by different means as per the demand and agricultural need. The review was also effective in explaining the different types of carriers in formulation giving different type of efficiency rate of inoculants and different efficiency rate of pesticidal action. The methodology also exposed role of $\mathrm{Zn}$ and Fe Nanoparticles in agriculture depicting the application of Nanotechnology in the field. The commonest formulation used are depicted in the table below for better understanding (Table 1).

\section{The development of formulations}

Formulation is unifying the carrier with the bacterial strain in laboratory or by industrial process as told by Bashan., et al. 2016 [18].

The process was explained briefly in following points

- Isolation/screening of rhizosphere samples

- In vitro growth of the isolated/screened consortia as pure cultures

- Minimal formulation/No formulation 


\begin{tabular}{|c|c|c|}
\hline Carrier material & $\begin{array}{l}\text { Inoculant/ } \\
\text { bacterium }\end{array}$ & Characteristics \\
\hline $\begin{array}{l}\text { Sterilized oxalic acid industrial } \\
\text { waste }\end{array}$ & Rhizobium & $\begin{array}{l}\text { Seed inoculation } \\
\text { Rhizobium multiplication in carrier in ambient temperature up to } 90 \text { days. } \\
\text { Carrier sterilization contribute dsignificant increase in grain yield, nodule } \\
\text { number and nitrogen content [13] }\end{array}$ \\
\hline Alginate-Perlite dry granule & Rhizobium & $\begin{array}{l}\text { Soil inoculation } \\
\text { Rhizobium strains survived in dry granules beyond } 180 \text { days. } \\
\text { The inoculants can be stored in a dry state without losing much viability. }\end{array}$ \\
\hline Composted sawdust & $\begin{array}{l}\text { Bradyrhizobium } \\
\text { Rhizobium and } \\
\text { Azospirillum }\end{array}$ & $\begin{array}{l}\text { Seed inoculation } \\
\text { Good growth and survival of the inoculant strains [14]. }\end{array}$ \\
\hline $\begin{array}{l}\text { Agriperlite, Expanded clay, } \\
\text { Kaolin, Celite, Diatom, Porosil } \\
\text { MP, Micro-cel Vermiculite }\end{array}$ & $\begin{array}{l}\text { Agrobacterium } \\
\text { radiobacter } \mathrm{K} 84\end{array}$ & $\begin{array}{l}\text { Crown gall control [15] } \\
\text { Screening was performed to find improved formulation of K84 cells. } \\
\text { Effect of carriers to age, temperature and carrier water content on survival of } \\
\text { K84 was examined. }\end{array}$ \\
\hline $\begin{array}{l}\text { Cheese whey grown cells in } \\
\text { peat }\end{array}$ & Rhizobium meliloti & $\begin{array}{l}\text { Seed inoculation } \\
\text { Better survival at various temperature during storage, even under desiccation }\end{array}$ \\
\hline Mineral soils & Rhizobium & $\begin{array}{l}\text { Seed inoculants } \\
\text { Rhizobium survived better at } 4^{\circ} \mathrm{C} \text { than at higher temperature. }\end{array}$ \\
\hline Coal & Rhizobium & $\begin{array}{l}\text { Seed inoculants } \\
\text { Seven among eight tested coals supported the growth and survival of } R . p h a- \\
\text { seoli strains. Most contained more than } 107 \text { rhizobia per g after } 12 \text { months } \\
{[16] \text {. }}\end{array}$ \\
\hline $\begin{array}{l}\text { Granular inoculants amended } \\
\text { with nutrients }\end{array}$ & $\begin{array}{l}\text { Bradyrhizobium } \\
\quad \text { japonicum }\end{array}$ & $\begin{array}{l}\text { Soil inoculants } \\
\text { Betonite granules, elite and steatite granules, or silica granules amended with } \\
\text { glycerol, Naglutamate and inoculated with either peat or liquid Bradyrhizo- } \\
\text { bium japonicum inoculants. } \\
\text { Enhanced early nodulation of soybean and increased } \mathrm{N} \text { content of grain [17]. }\end{array}$ \\
\hline $\begin{array}{l}\text { Soybean oil or peanut oil } \\
\text { added with lyophilized cells }\end{array}$ & Rhizobium & $\begin{array}{l}\text { Seed inoculants } \\
\text { Provide more protection than peat-based inoculant when rhizobia are inocu- } \\
\text { lated on seeds and exposed to condition of drought and high temperature. }\end{array}$ \\
\hline Perlite & $\begin{array}{l}\text { Rhizobium, } \\
\text { Bradyrhizobium, } \\
\text { Bacillus }\end{array}$ & $\begin{array}{l}\text { Seed inoculants } \\
\text { Combination of a sucrose adhesive with the perlite carrier gave better survival } \\
\text { of bacteria on seeds Produced similar number of nodules, nodule dry weight, } \\
\text { crop yield and nitrogen content aspeat-based inoculants. }\end{array}$ \\
\hline
\end{tabular}

Table 1: Common carriers used in agriculture.

- $\quad$ Testing in lab conditions and field conditions

- Industrial release

- Industrial production of the identified microorganism

- Development of Formulation $\rightarrow$ Testing for shelf life/Patent

- Microplot field testing followed by Macroplot field testing

- $\quad$ Final testing in farmer's field $\rightarrow$ commercialization of product to be used in fields.
The formulation of carries can be in liquid form and solid form. Liquid carriers are formulated by using CMC and YEMM.. The Rhizobium formulation was made by using solid and liquid carriers by Ruíz-Valdiviezo., et al. 2015 [19]. The liquid carrier used in the study were CMCS (Carboxy methyl cellulose and Starch) and YEMM (YEM with Manitol).

The formation of formulation was reported in following points

- $\quad$ The identified Rhizobium strain was grown in Yeast Extract Manitol (YEM) media at $\mathrm{pH} 6.8$ at $28^{\circ} \mathrm{C}$ then stored at $4^{\circ} \mathrm{C}$ 
- $\quad$ CMCS was made by mixing Carboxy methyl cellulose (pH 10.8) with starch in 60:40 w/w ratio and then was amended with $\mathrm{MgO}$ at $1 \%$ to achieve the final concentration of $1.28 \% \mathrm{w} / \mathrm{v}$ and a $\mathrm{pH}$ of 6.7

- $\quad$ The YEMM carrier was prepared with $1.0 \mathrm{~g}$ of Yeast Extract, 0.1 $\mathrm{g} \mathrm{NaCl}, 0.5 \mathrm{~g} \mathrm{~K}_{2} \mathrm{HPO}_{4}, 0.2 \mathrm{~g} \mathrm{MgSO}_{4} .7 \mathrm{H}_{2} \mathrm{O}$ and $20 \mathrm{~g} \mathrm{Mannitol} / \mathrm{L}$ DW and adjusted to pH 6.7. Both CMCS and YEMM were sterilized at $121^{\circ} \mathrm{C}$ for $15 \mathrm{~min}$.

- The physical characteristics of the carriers were determined each time they were in contact with Rhizobia. The Liquid carriers as in CMCS and YEMM were tested for $\mathrm{pH}$ and Viscosity. Similarly, Solid carriers were formulated by using Peat, PSB, Biochar. Like the above-mentioned liquid carriers RuízValdiviezo., et al. 2015 [19], also formulated Rhizobial strain on solid carrier like PEAT and PSB.

The group used following methodology for carrier preparation

- $\quad$ PSB (pH 7.7) was made by mixing sugarcane bagass and perlite in ratio of $4: 1$.

- $\mathrm{pH}$ of Peat was 3.8 adjusted to 6.7 by $35 \mathrm{~g}$ of $\mathrm{Na}_{2} \mathrm{Co}_{3}$.

- $\quad$ Peat and PSB both were first grinded then sieved from mesh with mesh size of 100 followed by their sterilization at $121^{\circ} \mathrm{C}$ for $20 \mathrm{~min}$.

- $\quad$ The Solid carriers as in Peat and PSB were tested for $\mathrm{pH}$ and water holding capacity every time when they came in contact with the Rhizobial strain..

Similarly one years back Biochar was used as carrier by Głodowska., et al. 2016 [20] for Pseudomonas libanensis on Corn plant and the following ways were used:

- Pseudomonas libanensis strain isolated from soybean rhizosphere was cultured on King's B medium (20 g peptone, 1.5 $\mathrm{g} \mathrm{MgSO}_{4}, 1.5 \mathrm{~g} \mathrm{~K}_{2} \mathrm{HPO}, 10 \mathrm{~mL}$ glycerol L-1 distilled water) at pH 7.0 followed by incubation for 7 days at $25^{\circ} \mathrm{C}$ in dark under shaking conditions.

- $\quad$ The log phase culture was plated on Petri plate for testing the viable cells by the capacity of the strain to solubilize inorganic phosphate in a solid medium.

- $\quad$ Four Biochar were taken, two each from hardwood feed stock and softwood feed stock.

- $\quad$ Peat moss was taken as testing carrier or a standard inoculant carrier/control so that efficacy of Biochar is proven.

- $200 \mathrm{~g}$ of each material was oven dried at $75^{\circ} \mathrm{C}$ for 3 days and the material was then grinded, powdered and sieved with mesh size of $500 \mu \mathrm{m}$.

- The carriers were then bagged in polypropylene and autoclaved for 3 days at $121^{\circ} \mathrm{C}$ for $20 \mathrm{~min}$.

- $\quad$ Being the solid carrier their $\mathrm{pH}$ and water holding capacity were determined every time they came in contact with $P$. libanensis strain.
The formulation of carriers can be just by mixing the two compatible microbial flora together. There are two such type of formulation discussed here.

- In the case of rhizobium all the carriers were inoculated with $1.5 \mathrm{~mL}$ inoculant/g under sterile conditions. Out of this $25 \mathrm{~g}$ solid and $25 \mathrm{~mL}$ liquid biofertilizers were added to sterilize polypropylene bags $(20 \mathrm{~cm} \times 30 \mathrm{~cm})$ and stored at $25^{\circ} \mathrm{C}$.

- $\quad$ Similarly P. Libanensis culture (1.2 mL) in late log phase was aseptically injected with $11 \mathrm{~mL}$ of sterile water into sterilized bags with $30 \mathrm{~g}$ of carrier, manually mixed, and sealed with clips at room temperature $\left(21^{\circ} \mathrm{C}\right)$.

\section{The Comparative analysis of different formulation}

When there are different types of carriers, which one is better for the crop is difficult to decide. So different formulation and different carriers and different microbial flora was comparatively analyzed. The development of formulation with carrier and bacterial strain in laboratory or by industrial process has already been discussed [21]. Further the analysis of different support system for effective carrier formulation or different microbial combinations was analyzed by checking the test crop yield efficiency as in

- $\quad$ Comparative analysis of PSB (Phosphate Solubilizing Bacteria) on different carriers like Coir-pith, Vermi-compost, Organic manure, Lignite, Vermiculite. The carriers were first sterilized and then bioinoculants were isolated and multiplied in Hydroxy Petite medium. The carriers were sterilized and used for mass multiplication where in a viable count ranged from 109 to 1010/ ml-1 were preferred for the preparations of bioformulation. The population was attained in 3 - 5 days in the case of fast growing organisms such as Pseudomonas and Bacillus. Three-day old culture was mixed with the sterilized carrier materials and air dried under shade condition and used for nursery experiments [22].

- $\quad$ Comparative analysis of the different carriers in different formulation of Rhizobium strain and Pseudomonas strain. The Rhizobium strain and Pseudomonas strain was grown on YEMA media; King's B media respectively. The bioinoculants were prepared in three different manners (Rhizobium strain and Pseudomonas strain and their consortium) impregnated with different carriers i.e. Saw Dust, Wood ashes, Sand, Bagasse and Coriander husk. For this $10 \mathrm{~g}$ of Carrier material were taken in disposable glasses and to this $10^{8} \mathrm{ml}^{-1}$ of Rhizobium strain and Pseudomonas strain and their consortium were added in triplicates and tested for water holding capacity for 5 weeks where every viable cell count was tested that is done by adding $1 \mathrm{~g}$ of formulation to $9 \mathrm{ml}$ of water and serial diluted it till $10^{-10}$ to remove carrier and from it 10 microliter was taken for testing in by colony counting method in minimal salt agar medium at $28^{\circ} \mathrm{C}$ for $24 \mathrm{~h}[23]$. 
- $\quad$ Comparative analysis of the different enrichment material in different formulation of Rhizobium strain and Pseudomonas strain. The strains were Rhizobium strain and Pseudomonas strain were grown on their respective media of YEMA and King's B media but here for tracking the populations of bacteria in bioformulation, antibiotic resistance was also introduced in both the strains. Escherichia coli WA803 having suicidal plasmid (pGS9) integrated into a transposon Tn5 with a kanamycin-resistant and streptomycin-resistant marker gene was used to confer kanamycin resistance to Rhizobium and streptomycin resistance to Pseudomonas respectively [24]. After $48 \mathrm{~h}$ culture was added in each carrier on the basis of their water holding capacity in three sets, (i) Carrier + Rhizobium, (ii) Carrier + Pseudomonas, and (iii) Carrier + consortium. Saw dust (SD) since had highest water holding capacity than others was selected for making the bioformulation with different combinations of microbes and enrichment material Carboxymethyl cellulose (CMC), sucrose, molasses and gum arabic.enrichment martial was mixed in sawdust at $1 \%$ concentration $(\mathrm{w} / \mathrm{w})$. The experiment was conducted in triplicates and one bag of each carrier from each triplicate was studied after every 30 days up to 180 days [25].

\section{The study of test crop response and shelf life of inoculant}

The test crop response was calibrated by different growth parameters and biochemical estimations when crop is grown under sterile soil conditions. Similarly, the shelf life was calculated by CFU/g after every fixed period of time by standard protocols [26]. The response of PSB (Phosphate Solubilizing Bacteria), Rhizobium on the test crop were tested with above carrier formulations and were put to growth for a week and after one week, the test crop was tested on following growth parameters for shoot length, root length, plant fresh and dry weight in both control (without formulation) and treated plant. The biochemical tests were done for chlorophyll, protein, glucose, free amino acid and nitrate reductase activity estimations were analyzed. Further analyses were done in different enrichment media where test crop response and shelf life of the formulations with carrier were tested. The test crop was raised from surface sterilized seeds on steam sterilized local soil (500 g; $\mathrm{P}=0.0908 \%, \mathrm{pH}=8.4$ ), but before this formulation was tested for shelf life, after every 30 days samples were checked for measuring colony forming units (CFU) up to six months. The formulation was added in form of slurry (25\% F: $1 \% \mathrm{~W}$ ) enriched with some enrichment media. The seeds for the test crop were soaked for $10 \mathrm{~min}$ in this formulation and then dried under sterilized conditions. The experiment was carried out with fifteen different treatments of saw dust bioformulation: (i) Seeds + Rhizobium strain(ii) Seeds + Pseudomonas strain (iii) Seeds consortium (iv) Seeds + $\mathrm{CMC}+$ Rhizobium strain (v) Seeds + CMC + Pseudomonas strain (vi) Seeds + CMC + consortia. Similar sets were made for other enrichment materials (sucrose, molasses and gum). Seeds without any treatment were taken as control. After (60 days) or at harvest, root length, shoot length, nodule number per plant, fresh weight and dry weight were determined. Chlorophyll content of chickpea leaves was estimated [27].

\section{The carriers as Biopesticides}

This is another aspect of Carriers apart from nourishment, they can act as effective biopesticide agent also. Carrier as biopesticide in substrate adhesive organic solid formulation with different solid organic substrates was developed with an objective to evaluate the pesticidal action of different formulations with $P$. fluorescence as a potential biocontrol agent. The study detailed following aspects [28].

- Source, isolation and preservation of pathogen $R$. soIanacearum: The eggplant with typical symptoms of wilting were collected and their stems were obliquely cut and placed in sterile water. The stems that oozed out milky substance in water were selected and grown on sterile agar media with triphenyl tetrazolium chloride. The selected inoculum was maintained in sterile water and refrigerated at 200C.

- Collection and isolation of $P$. fluorescence and preparation of cell suspension of pathogen and microbe: The isolated and characterized strain was grown on King's B media and maintained in King's B agar slants. The suspension of bacteria and pathogenic fungi was then harvested in $10 \mathrm{~mL}$ sterile water and serially diluted. The concentration of $108 \mathrm{cfu} / \mathrm{mL}$ was finally selected for further use. The biocontrol activity and MIC was calculated by paper disc method [29].

- Collection and preparation of different organic substrates for multiplication of $\boldsymbol{P}$. fluorescence: The different organic substrates selected were rice bran, wheat bran, farmyard manure, vermicompost, rice straw and decomposed mustard oil cake. The adhesives used were CMC, PVA and wheat flour gum. The substrates were air dried, grinded and packed in polypropylene sleeves filled with $10 \mathrm{~mL}$ of sterile DW, weighing $100 \mathrm{~g}$ each, to which adhesives were added to prepare different mixtures in 1:10 v/w. The $\mathrm{pH}$ was adjusted to 7 by $\mathrm{CaCO}_{3}$ and the mixture was heat sealed and sterilized at $1210 \mathrm{C}$ for $30 \mathrm{~min}$. The sterilized mixture was then spread on sterilized disposable non sticky plate with help of sterilized spoon. To this Mannitol was added as osmoticum (8.5mL of 3\% Mannitol for $100 \mathrm{~g}$ formulation). Finally the suspension of $P$. fluorescens concentration of $108 \mathrm{cfu} / \mathrm{mL}$ was added in ratio of $1: 10 \mathrm{v} / \mathrm{w}$ and thoroughly mixed with spoon. The formulation so prepared was now spread on another sterilized non sticky plate and covered with another sterilized plate was then incubated and allowed to dry for 3 days at room temperature. In similar ways other formulations were made and stored at 40C for further comparative study.

- Evaluation of different formulation Pseudomonas strain with respect to biocontrol activity: The five best formulations were selected days after storage as per viability on the basis of shelf life in the different carriers. To test their biocontrol activity on bacterial wilt of eggplant, a potting media of humus, clay and peat in the ratio of 15:35:50 was sterilized and filled in the earthen pots with sand in 
ratio of 1:3. The treatment from each formulation was in three ways, seed, root and soil and their combinations. There were two controls, one control was inoculated with only pathogen without formulation and other control was inoculated with formulation but without pathogen. The test crops were infected with $R$. Solanacearum after 15 days and the disease was recorded for 90 days by following formula: wilt incidence $=\%$ (No. of wilted plants in each treatment- No. of plants with formulation)/ Total no. of plants receiving treatment)*100.

- Carrier as biopesticide in liquid formulation: The liquid formulations are usually microbial cultures in form of suspensions, emulsions, concentrates, oil dispersions, sups-emulsions and capsule suspension. The formulation is enhanced with nutrients, cell protectants and inducers responsible for cell spore/ cyst formation. The microbial suspension is either a broth, or in sterile water or in mineral and organic oil. The various additives like CMC, Glycerol, and PVP were used as osmoticum and for strengthening the formulation in ratio of 1:10. The microbial culture for formulation was selected as $107 \mathrm{cfu} / \mathrm{mL}$. The old culture was preferred having sporulation or cyst stage so that when it becomes the part of formulation it enters the active stage. 180th day culture are preferred for formulation.

- Carrier as biopesticide in dust formulation: Callosobruchus maculatus was grown on black gram seed in glass jar covered with muslin cloth [4]. Further a dust formulation of $P$. nigrum seed and fly ash were mixed in ratio of 1:9 and MIC was tested in open and closed environment [30]. In open environment the black gram seeds with dust formulation were infested with newly produced insect in petridish and in close environment the black gram seed with dust was kept in sealed bottles and each bottle was infested with single newly produced beetle. The triplets for each condition were kept under ambient room temperature conditions and generation study assay was done to see the effect of dust in number of generations. After third day beetles were released and numbers of eggs were counted on the seeds. After $5^{\text {th }}$ day the number of unhatched translucent eggs and opaque hatched eggs were counted, thereby giving hatchability percentage. On $15^{\text {th }}$ day all dead insects were removed so that they do not blend with F1 offspring so that survival percentage could be calculated. The newly emerged young ones were removed once in every three days till all the F1 offspring emerge after 60 days. The observations were made on $60^{\text {th }}$ day after treatment in form of number of damaged and undamaged seeds.

\section{The role of Nanotechnology in plant agro system}

These days the world where everything is using nanotechnology for betterment, the same was used in formation of carriers too. The development of Zn-Nanofertilizer synthesized from cell free filtrate of Rhizoctonia bataticola procured from NCBI has been tested as effective carriers. The fungus was grown in 250-mL Erlenmeyer flask containing 100-mL Potato Dextrose broth medium and $\mathrm{pH}$ was adjusted to 5.8. The culture was left to grow under shaking conditions of $28^{\circ} \mathrm{C}$ for $72 \mathrm{~h}$ at $150 \mathrm{rpm}$. The fungal balls so obtained were filtered and the separated mycelia were washed thrice DDW. The harvested mycelia were suspended in $100 \mathrm{~mL}$ sterile water and again kept for incubation under shaking conditions for $12 \mathrm{~h}$ this time, followed by filtration with fine filters. This cell free filtrate was used in production of Zn-NP, by adding aqueous solution of Zinc Oxide and making the final concentration of $0.1 \mathrm{mM}$. The entire solution was kept under shaking conditions at $280 \mathrm{C}$ for $4 \mathrm{~h}$. After every $1 \mathrm{~h}$ the part was taken out for the characterization of the particles formed due to biotransformation. Further the effect was studied on a common cash crop, Pearl Millet. The experiment was carried out under three conditions of control (without any treatment), ordinary size ZnO and Zn-NP as Zinc nanofertilizer., with latter two giving treatment by foliar application (16 L ha-1) after 2 week of germination at a concentration of $10 \mathrm{mg} \mathrm{L-1}$, which was an optimum dose [30]. After 4 weeks of the plants were uprooted and planted in the crop field to be harvested after maturity. The root and shoot parameters along with other biochemical parameters like total chlorophyll content, total soluble leaf protein content and in rhizosphere, enzyme activity of dehydrogenase, acid and alkaline phosphatase and phytase were also assayed [32]. On similar ground another nanoparticle carrier was Fe-NP as nanofertilizer on the crop growth: A field experiment was carried out during two growing seasons and the soil characteristics were recorded before the treatment and it was found that the soil is loamy with portion of silt and clay and $\mathrm{pH}=7.3-7.8$. The electrical conductivity $(\mathrm{EC})=1.2$ $1.4 \mathrm{dS} \mathrm{m}^{-1}$ or $1.2-1.4 \mathrm{mmho} / \mathrm{cm}$ and $0.9 \%$ organic matter, and contained $4.75 \mathrm{mg} \mathrm{kg}^{-1}$ iron. The mean annual precipitation and mean annual temperature were $159 \mathrm{~mm}$ and $15.4^{\circ} \mathrm{C}$, respectively The experiment were set with three sources of Fe- fertilizers (Fe-NP, $\left.\mathrm{Fe}_{\mathrm{x}} \mathrm{O}_{\mathrm{y}}, \mathrm{Fe}_{\mathrm{x}} \mathrm{SO}_{4}\right)$ in concentration of $2 \mathrm{~g} \mathrm{~L}^{-1}\left(0.28 \mathrm{~kg} \mathrm{ha}^{-1}\right)$ and $4 \mathrm{~g} \mathrm{~L}-1$ $\left(0.56 \mathrm{~kg} \mathrm{ha}^{-1}\right)$; 4 and $8 \mathrm{~g} \mathrm{~L}^{-1}\left(1.1 \mathrm{~kg} \mathrm{ha}^{-1}\right)$; and 4 and $8 \mathrm{~g} \mathrm{~L}^{-1}$, respectively all being foliar treatments, out of which $50 \%$ was sprayed at stem elongation and $50 \%$ at time of flowering with same amount of water sprayed on control. Different plots with sufficient supply of chemical fertilizers like Urea was created before sowing the seeds. Then at the maturity stage ten plants from each row were selected and growth parameters were studied [33]. After full maturity at the time of harvesting the plants harvest index was calculated as ratio of grain yield to biological yield. The other biochemistry that was assayed were, grain iron content, chlorophyll and carotenoid content, total protein content, total carbohydrate content and enzymatic assay of peroxidases and catalases.

\section{Conclusion}

The need to produce good formulation is to cause effective inoculation of PGB into soil or to increase the shelf life in post harvesting conditions. To produce an effective formulation the identified microorganism is bind to either sterile carrier or non-sterile carrier where sterile carrier has better advantages as it delivers the desired microorganism at site of delivery in precise concentration that avoids the otherwise suppression of cell numbers by indigenous population [34]. Secondly it raises the inoculum potential. Thus, it can be sufficed that a good Inoculant is one that has good formulation (Bacteria+Carrier) and Good Formulation needs good and stable Carrier. Sometimes an adhesive is required to bind the 
carrier effectively such as Glycerol in solid formulation and Gum Arabic in case of liquid formulation.

As discussed earlier a good carrier is an important factor for good formulation. There are so many carriers available in the market but to select the one best for the agriculture largely depends on the efficacy of Bioinoculants in form of Biofertilizers. The commonly available biofertilizers are biological nitrogen fixers and phosphate solubilizers. Phosphate solubilizing biofertilizers (PSB) are carrier-based preparation containing living cells of microorganisms like bacteria, fungi and actinomycetes which help in increasing crop productivity by way of helping in solubilization of insoluble phosphorus, stimulating plant growth by providing hormones, vitamins and other growth factors.

Their efficiency largely depends on their formulation and all efforts are made to increase their shelf life so that they can be stored as part of post-harvest technology. This shelf life is defined as the colony forming units/ml of sample after time ' $\mathrm{t}$ '. If the CFU/g is more, then the shelf life is high and if less, then shelf life is less and formulation has to be re-defined. The quantity of the bacterial sample to be mixed largely depends on the water holding capacity of the carrier so it's the carrier that decides the number of bacteria to be added to the formulation to maintain the consistency.

Similarly, the various nitrogen fixers are also being used as carrier formulation and their shelf life was also increased by impregnating them to best carriers like saw dust with high water holding capacity. Both the types of fertilizers were tested for crop response and other biochemical activities because it is via the growth of plant in formulated conditions and control conditions without formulation will depict the difference, thereby proving the efficient use of the formulation.

If some enrichment media like molasses etc. is also added to the formulation then formulation is further enhanced and tested under growth parameter. These enrichment media support the growth of the bacteria present in the formulation and thus it also helps in maintaining the cell viability that in turn increases the shelf life. If such formulation acts as bioinoculant then the growth response of the test crop is always to be higher than the growth response of the bioinoculant without enrichment media.

Another role of carriers as biopesticide can be used in different form of formulation. The reason behind the carriers being effective biopesticide is same as for carriers as effective biofertilizers. The carriers in solid formulation provide different biocontrol rate with different carriers and again peat is proven to be the best carrier for solid formulation.

The inoculum however is fixed to $107-108 \mathrm{cfu} / \mathrm{mL}$ in the carrier substrate in the ratio of either $1: 10$ or $1: 9$.

The minimum inhibitory concentration is also calibrated so that the doses are defined for the biocontrol activity. These MIC help in dose dependent biocontrol activity thus the stability in the field environment is standardised.
Secondly the carriers are mixed with additives like CMC so that the osmoticum is maintained and the inoculum survives even in dry conditions providing longer shelf life. Thirdly for biopesticide the inoculum should be old and sporulating so that the cyst/ spore when mixed with carriers and additives enter into the log phase providing exponential growth with production of metabolites that trigger biocontrol activity rapidly.

The host to pathogen interaction is the basic requisite for developing an effective biopesticide. Therefore, the biochemistry behind pathogenicity helps in targeting the stage for biocontrol. The microbe, the carrier and the additive are selected on the basis of the type of biocontrol that has to be done. Thus, if the pathogenicity involves root penetration then biocontrol should be around root protection and preventing the pathogen to penetrate the root. The other agricultural enhancement is application of nanoparticles as fertilizers [35]. These nanoparticles are reported of being small in size with large surface area that gives them an edge over biofertilizers too that have poor efficiency because of poor incorporation in soil and low absorption rate. The matter shows extraordinary properties at the nanoscale as that shown by bulk materials. If the soil are brought to the nanoscale then the properties like surface area, cation exchange capacity, ion adsorption, complex formations and transformations, and many more functions would show thousand fold increment, which is because in case of nanomaterial it is high proportion of atom reacting on large surface area giving larger amount of reaction centers. It is because of this every nanoparticle has different surface composition, different types, densities and reaction sites even if produced from same element. These properties of nanoparticles make them react differently with respect to adsorption and various redox reactions occurring in nature and this was beneficial for use in agriculture [36].

The generalised result for the review suggests that the carriers in different formulation show effective biocontrol activity too and with the help of nanotechnology, the agriculture needs can be effectively met.

It was deduced from the development of formulation about the effective ways and possibilities of developing an effective formulation. It also states about the various carriers in formulation that produce good inoculants as part of green practice in sustainable agriculture [37]. The efficiency of two solid carriers, Biochar and Peat, where latter is nontoxic, economical, environmentally safe, physically and chemically stable and has high water holding capacity, still Biochar can lead to enhancement of corn plant growth without increasing the Phosphorous concentration of the plant [38]. This is because the Biochar has high water holding capacity and it may also act as a nutrient source for plant growth, so Peat acted as control carrier to test and compare the efficacy of Biochar. It was also reported that enrichment media also enhanced the shelf life of the formulation.

The review suggests that the carriers in different formulation show effective biocontrol activity. Secondly the properties of good carriers help in development of biopesticide as the host pathogen 
interaction helped in designing of the formulation [39]. Lastly the review helped in exploring the nanoparticles as carriers. It was found that they not only acted as effective carriers but were good nanofertilizers too.

The gain was by fold thousand times in both the tested crops as compared to control, but these parameters decreased at the higher rate of Fe-Np particles and Zn-Np stating their controlled application in optimum concentration.

In practical terms, to conclude the chosen formulation and method of application determine the potential success of the inoculant. As it can be deduced from the papers dealing with rhizobium and Pseudomonas sp. the role of carrier is very important for good formulation. In former one solid carrier Peat and PSB was far better than liquid carrier CMCS and YEMM whereas in latter one it was reverse Biochar was better than Peat Moss as solid carrier. It also draws light on use of nanoparticles as carriers.

But there are certain shortcomings that add to the future concern. There are many potential PGPR that can make excellent formulation but if to believe the scientific literature that indicates that many potentially highly useful strains did not appear on the commercial market because of inappropriate formulation and thus they are lost or forgotten. Secondly if good formulation qualities are discussed then obviously, no single inoculant can have all the capacities at top-end quality. However it should be practised that a good inoculant should have as many as possible of the desired features at reasonable quality.

Further, by utilizing high amount of agricultural and industrial waste as carriers like coriander husk, coirpithor use of Molasses as enrichment mediacan lead to fruitful step in solid waste management.

The use of carriers as biopesticide and nanoparticles as carriers. The additives enhanced the biocontrol activity and the use of nanoparticles together add to the different steps being taken in the field of green practices for crop enhancement and crop protection [40].

Lastly to summarise, the performance of a formulation is often the most common barrier for commercialization of inoculants because its foremost application is in the farmer's land. A microbial strain or nanoparticle may function optimally in vitro under the technical precision and set laboratory conditions in an affordable product for commercial purpose, yet In vivo the scenario is different as the formulation has to be used by scientifically unskilled farmers, under field condition without any technical expertise. Soto expect the similar result is a difficult task but for sure the use of carriers can contribute largely to green revolution approach that will have a great impact in agriculture.

\section{Bibliography}

1. http://www.worldpopulationbalance.org

2. Gould Fred. "The evolutionary potential of crop pests". American Scientist 79.6 (1991): 496-507.
3. Ortiz-Hernández., et al. "Pesticide biodegradation: Mechanisms, genetics and strategies to enhance the process". Biodegradation-life of science (2013): 251-287.

4. Gašić, Slavica and Brankica Tanović. "Biopesticide formulations, possibility of application and future trends". Pesticidiifitomedicina 28.2 (2013): 97-102.

5. Usta Canan. "Microorganisms in biological pest control-a review (bacterial toxin application and effect of environmental factors)". Current Progress in Biological Research, Eds., Marina Silva-Opps, InTech Publishers (2013): 287-317.

6. Malusá E., et al. "Technologies for beneficial microorganisms inocula used as biofertilizers". The Scientific World Journal 2012 (2012).

7. Somasegaran Padma and Heinz J Hoben. "Handbook for rhizobia: methods in legume Rhizobium technology". Springer Science and Business Media (2012).

8. Jones RW., et al. "Lignite and stillage: Carrier and substrate for application of fungal biocontrol agents to soil". Phytopathology 74.10 (1984): 1167-1170.

9. Bashan Yoav. "Inoculants of plant growth-promoting bacteria for use in agriculture”. Biotechnology advances 16.4 (1998): 729-770.

10. Tensingh Baliah $\mathrm{N}$ and $\mathrm{P}$ Jeeva. "Isolation, identification and characterization of phosphate solubilizing bacteria isolated from economically important tree species". I.J.S.N. 7.4 (2016): 870-876.

11. Yu Xuan., et al. "Isolation and characterization of phosphatesolubilizing bacteria from walnut and their effect on growth and phosphorus mobilization". Biology and Fertility of Soils 47.4 (2011): 437-446.

12. Dasgupta., et al. "Nanotechnology in agro-food: from field to plate". Food Research International 69 (2015): 381-400.

13. Kaushal., et al. "Oxalic acid industrial waste as a carrier for Rhizobium inoculants and its effect on soybean". Journal of the Indian Society of Soil Science 44.2 (1996): 249-252.

14. Kostov $\mathrm{O}$ and JM Lynch. "Composted sawdust as a carrier for Bradyrhizobium, Rhizobium and Azospirillum in crop inoculation". World Journal of Microbiology and Biotechnology 14.3 (1998): 389-397.

15. Pesenti-Barili BE., et al. "Survival of Agrobacterium radiobacter K84 on various carriers for crown gall control". Applied and Environmental Microbiology 57.7 (1991): 2047-2051.

16. Paczkowski Mary W and DL Berryhill. "Survival of Rhizobium phaseoli in coal-based legume inoculants". Applied and Environmental Microbiology 38.4 (1979): 612-615. 
17. Fouilleux Georges., et al. "Increase of Bradyrhizobium japonicum numbers in soils and enhanced nodulation of soybean (Glycine max (L) merr.) using granular inoculants amended with nutrients". FEMS microbiology ecology 20.3 (1996): 173183

18. Bashan., et al. "Advances in plant growth-promoting bacterial inoculant technology: formulations and practical perspectives (1998-2013)". Plant and Soil 378.1-2 (2014): 1-33.

19. Ruíz-Valdiviezo., et al. "Symbiotic potential and survival of native rhizobia kept on different carriers". Brazilian Journal of Microbiology 46.3 (2015): 735-742.

20. Głodowska., et al. "Biochar is a growth-promoting alternative to peat moss for the inoculation of corn with a pseudomonad". Agronomy for sustainable development 36.1 (2016): 1-10.

21. Deshwal V K., et al. "Rhizobia unique plant growth promoting rhizobacteria: a review". International Journal of Life Science (Nepal) 2.2 (2013): 74-86

22. Arora Naveen Kumar, et al. "Comparative study of different carriers inoculated with nodule forming and free living plant growth promoting bacteria suitable for sustainable agriculture". Journal of Plant Pathology and Microbiology 5 (2014): 229.

23. Baliah NT., et al. "Crop Response of Different Formulation of Phosphate Solubilizing Bacteria on Cow Pea”. International Journal of Current Advanced Research 5 (2016): 924-928.

24. Somasegaran Padma and Heinz J Hoben. "Handbook for rhizobia: methods in legume Rhizobium technology". Springer Science and Business Media (2012).

25. Singh S., et al. "Effect of enrichment material on the shelf life and field efficiency of bioformulation of Rhizobium sp. and Psolubilizing Pseudomonas fluorescens". Science Research Reporter 4.1 (2014): 44-50.

26. Arnon Daniel I. "Copper enzymes in isolated chloroplasts Polyphenoloxidase in Beta vulgaris". Plant physiology 24.1 (1949): 1.

27. Chakravarty Gargi and MC Kalita. "Comparative evaluation of organic formulations of Pseudomonas fluorescens based biopesticides and their application in the management of bacterial wilt of brinjal (Solanum melongena L.)". African Journal of Biotechnology 10.37 (2011): 7174-7182.

28. Rao Mahendrakar Sreenivasa., et al. "A frontier area of research on liquid biopesticides: the way forward for sustainable agriculture in India". Current Science 108 (2015): 15901592.

29. Blair JE., et al. "Laboratory Exercise in Microbiology (Ed. Pelczar MJ, Chan EC)”. Mc. Graw Hill Book Co., Berlin (1971): 356
30. Govindan K., et al. "Fly ash-Excellent filler for black pepper, Piper nigrum dust formulation against Callosobruchus maculatus (F.)". Journal of Biopesticides 3.1 (2010): 320-324.

31. Tarafdar JC., et al. "Development of zinc nanofertilizer to enhance crop production in pearl millet (Pennisetumamericanum)”. Agricultural Research 3.3 (2014): 257-262.

32. Tabatabai MA and JM Bremner. "Use of p-nitrophenyl phosphate for assay of soil phosphatase activity". Soil biology and biochemistry 1.4 (1969): 301-307.

33. Razmjoo J and H Ghafari. "Response of durum wheat to foliar application of varied sources and rates of iron fertilizers". Journal of Agricultural Science and Technology 17.2 (2015): 321-331.

34. Kloepper JW and MN Schroth. "Development of a powder formulation of rhizobacteria for inoculation of potato seed pieces". Phytopathology 71.6 (1981): 590-592.

35. Mukhopadhyay Siddhartha S. "Nanotechnology in agriculture: prospects and constraints". Nanotechnology, Science and Applications 7 (2014): 63.

36. Hochella Michael F., et al. "Nanominerals, mineral nanoparticles, and earth systems". Science 319.5870 (2008): 16311635.

37. Manikandan R., et al. "Standardization of liquid formulation of Pseudomonas fluorescens Pf1 for its efficacy against Fusarium wilt of tomato". Biological control 54.2 (2010): 83-89.

38. Credland Peter F and Andrew W Wright. "Factors affecting female fecundity in the cowpea seed beetle, Callosobruchus maculatus (Coleoptera: Bruchidae)". Journal of Stored Products Research 25.3 (1989): 125-136.

39. Srinivasan K and N Mathivanan. "Plant growth promoting microbial consortia mediated classical biocontrol of sunflower necrosis virus disease". Journal of Biopesticides 4 (2011): 6572.

40. Mishra., et al. "Biopesticides: Where We Stand". In Plant Microbes Symbiosis: Applied Facets (2015): 37-75.

\section{Volume 3 Issue 11 November 2019}

(C) All rights are reserved by Rajiv Dutta., et al. 